\title{
An improved technique for measuring absorption coefficients of masonry building materials
}

\author{
Toby Cambray ${ }^{\mathrm{a}}$, Olivia de Sousa Costa ${ }^{\mathrm{b}}$ \\ a. University College, London; Greengauge Building Energy Consultants, Bradford on Avon, UK \\ b. Greengauge Building Energy Consultants, Bradford on Avon, UK
}

\begin{abstract}
Hygrothermal simulation is an important tool in the practice and policy of deep energy retrofit and other aspects of design. A key constraint on its use is availability of material data, in particular absorption coefficient. Practitioners must usually select data from databases with little or no useful information for historic materials. Improved automatic methods, such as those used here, have existed for over two decades; a further refinement is proposed. Data for two types of limestone from Lincolnshire, UK are presented, and the automatic method is compared with the manual method.
\end{abstract}

Peer-review under the responsibility of the organizing committee of the ICMB21.

Keywords: absorption coefficient; alpha value; hygrothermal; building material

\section{Introduction and Aim}

Hygrothermal simulation in accordance with [1] is an important technique to assess the moisture risk of build-ups. Reliable results require appropriate material properties, an important parameter being the absorption coefficient. Users of WUFI [2], for example, are advised to use methods specified in [3] to obtain liquid transfer coefficients. This standard calls for large samples such as whole bricks, and specifies the calculation of absorption coefficient in a way that is not suitable for smaller samples. This extended abstract demonstrates an alternative method which has advantages for samples of all sizes, particularly smaller samples with a mass less than $100 \mathrm{~g}$. Data for two types of English limestone are presented.

\section{Literature}

There are many methods in which to measure the absorption coefficient of a material including measuring electrical resistance and X-ray tomography [4], and gravimetric approaches [5,6,7,8]. The earliest proposal we know of for an automatic gravimetric method was in [9]. Feng and Janssen [8] discuss the way such experiments are carried out and codified, including the sensitivity to a variety of factors and the processing of results.

\section{Methodology}

The experimental techniques are similar to those described in [9] and recently elaborated in [6]. Cylindrical samples ( 45mm diameter) are suspended a balance, with the bottom surface in contact with a water bath as shown in Figure 1 (to approximate 1D flow); the mass is recorded at suitable frequency e.g. every $5 \mathrm{~s}$. Other authors employ various complex arrangements for maintaining a constant water level. Instead, we propose that the surface area of the bath is large in relation to the sample, such that the volume of water absorbed has a negligeable effect on the water depth. However this

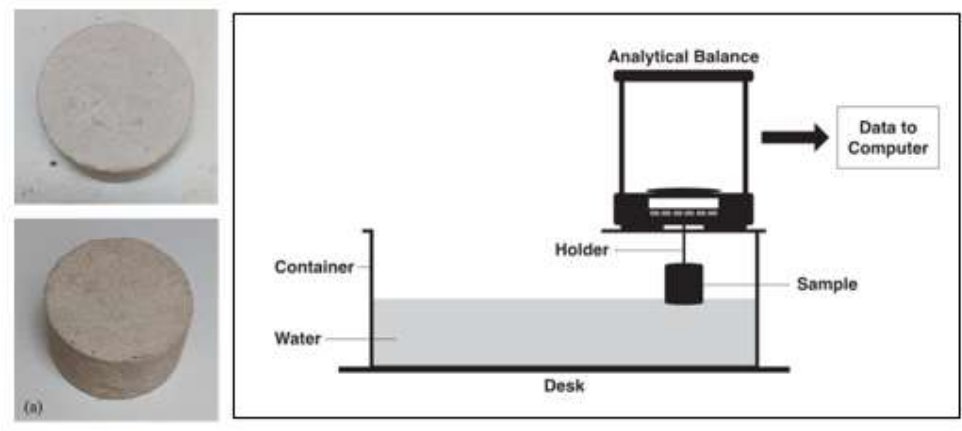

Figure 1. Example of samples (left) and apparatus set-up for testing (right). increases the rate of latent cooling discussed in [8]; this could be mitigated via heating of the bath, and/or completing the experiment within a chamber with high humidity. The slope of mass increase with the square root of time during initial wetting gives the 'absorption coefficient' although the precise definition varies [8].

Seven samples comprising two types of limestone were obtained from a building near Grantham, Lincolnshire. The type of stone and likely source was identified by visual inspection with reference to [10]. For practitioners it is helpful to provide positive identification or other meta data about samples to help select appropriate material data for particular situations. Unfortunately this meta data is often not provided or is insufficient, so it is impossible to select data on the basis of basic observations such as location, appearance, age of the building of interest and so on. As shown here, there can be significant variation in properties within broad categories or locations of material such as 'Lincolnshire limestone'.

Toby Cambray is a doctoral research student at UCL and a Director of Greengauge Building Energy Consultants.

Olivia de Sousa Costa is a Building Physicist at Greengauge Building Energy Consultants who specialises in moisture risk.

(C) The Author(s). This is an open access article distributed under the terms of the Creative Commons Attribution Licence (CC BY) 4.0 https://creativecommons.org/licenses/by/4.0/, which permits unrestricted use, distribution and reproduction in any medium, provided the original author and source are credited. DOI: 10.14293/ICMB210077 


\section{ICMB21}

\section{Results and Discussion}

Table 1 presents the absorption values measured, as well as related properties of each of the samples. Figure 2 shows an example of the graph that is obtained from both the manual and automatic methods. One of each stone type is shown. The smaller points in each case show results from the automatic method, and the larger points are results obtained using the manual method. Sources of experimental error are discussed in [8]. Figure 2 shows the much greater volume of data points that can be collected using the automatic method, which reduces the uncertainty in fitting a slope. It also removes error associated with sample handling and wiping the sample as specified in [3].

\begin{tabular}{|c|c|c|c|c|c|c|c|}
\hline Stone Type & \multicolumn{4}{|c|}{ Oolitic Limestone: Ancaster Ragstone } & \multicolumn{3}{|c|}{ Ooidal Limestone: Hard White } \\
\hline Sample Number & 1 & 2 & 3 & 4 & 5 & 6 & 7 \\
\hline Bulk density $\left[\mathrm{kg} / \mathrm{m}^{3}\right]$ & 1800 & 2000 & 1900 & 1800 & 2600 & 2100 & 2300 \\
\hline Saturation water content $\left[\mathrm{kg} / \mathrm{m}^{3}\right]$ & 160 & 160 & 200 & 200 & 90 & 120 & 120 \\
\hline $\begin{array}{l}\begin{array}{l}\text { Absorption coefficient } \\
\text { method) }\left[\mathrm{kg} / \mathrm{m}^{2} \mathrm{~s}^{1 / 2}\right]\end{array} \\
\text { l }\end{array}$ & 0.041 & 0.055 & 0.081 & 0.069 & 0.030 & 0.054 & 0.043 \\
\hline $\begin{array}{l}\text { Absorption coefficient ('Automatic' method) } \\
{\left[\mathrm{kg} / \mathrm{m}^{2} \mathbf{s}^{1 / 2}\right]}\end{array}$ & 0.051 & 0.056 & 0.077 & 0.080 & 0.027 & 0.055 & 0.051 \\
\hline
\end{tabular}

Table 1. Summary of key properties for each of the stone samples tested.

There is reasonable agreement between the results of the two methods; the linear regression between the manual and automatic methods has a slope of 0.96 and an intercept of 0.0055 ; the $\mathrm{R}^{2}$ value is 0.88 . Further work would be necessary to explore the variance within and between these methods, expanding on the work presented in [8]

For some types of error, in particular those associated with manual handling of the samples and temporarily removing them from the water, the margins do not scale linearly, such that smaller samples are more vulnerable to experimental error [8]. In the context of heritage buildings, where it is often impractical or unacceptable to remove larger samples, techniques better suited to small samples are useful.

For practitioners undertaking hygrothermal simulation, the accuracy and precision requirements are often less demanding because the values measured are not used directly, but rather to guide selection of appropriate material data from a database. On the other hand, an important benefit of the automatic method for both practitioners and researchers is the convenience offered by the automatic method over the manual [6].

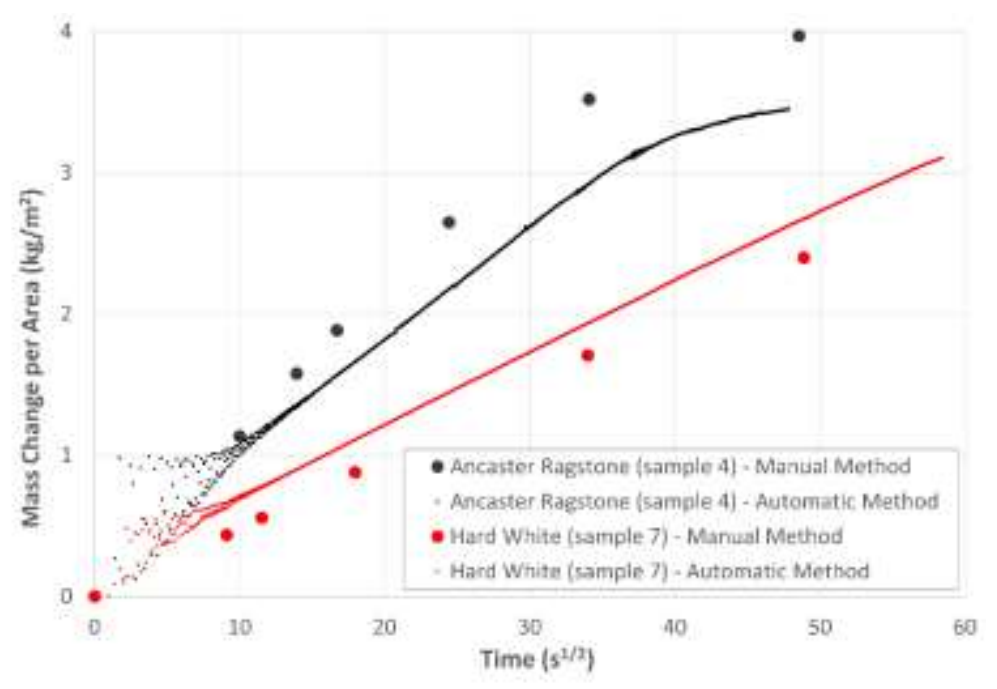

\section{Conclusions}

Absorption coefficient is an important parameter in hygrothermal simulation. Values for two known, contrasting types of limestone are presented. Two different experimental techniques are compared. The automatic method allows the absorption coefficient of smaller samples be measured with less experimental error and is more convenient. A simple approach to maintaining water bath level is proposed. Further work is required to quantify (and mitigate or account for) the errors introduced by latent cooling and small changes in water level. Variance within and between methods warrants further investigation.

\section{References}

[1] BSI (2007): BS EN 15026 (2007): Hygrothermal performance of building components and building element-Assessment of moisture transfer by numerical simulation

[2] Fraunhofer IBP, 2019. WUFI Pro 6.3 online help.

[3] BSI (2016): BS EN ISO 15148 (2016): Hygrothermal performance of building materials and products-Determination of water absorption coefficient by partial immersion

[4] W. Li, J., et al., 'Combining electrical resistance and 3-D X-ray computed tomography for moisture distribution measurements in wood products exposed in dynamic moisture conditions', Build. Environ. 67 (2013) 250-259.

[5] Djerbi Tegguer (2012), 'Determining the Water Absorption of Recycled Aggregates Utilizing Hydrostatic Weighing Approach', Construction and Building Materials 2/2012 pp112-116 DOI: https://doi.org/10.1016/j.conbuildmat.2011.08.018

[6] Lu. J, Wang. K, Qu. M, 'Experimental determination on the capillary water absorption coefficient of porous building materials: A comparison between the intermittent and continuous absorption tests.' Journal of Building Engineering 28 (2020)

[7] Hall, C. and Hoff, W., 2012. Water Transport In Brick, Stone And Concrete $2^{\text {nd }}$ Ed. London: Spon Press.

[8] Feng C, Janssen H, 'Experimental Stud on the capillary absorption characteristics of rammed earth.' Construction and Building Materials 283 (2021)

[9] Martín-Calleja, J., Mosquera, M., Merello, R., 1996. New method for performing capillary absorption test. American Ceramic Society Bulletin 75, 66-70.

[10] Strategic Stone Study (SSS) and English Building Stone Pits (EBSPits) Website MineralsUK [WWW Document], n.d. URL https://www2.bgs.ac.uk/mineralsuk/buildingStones/StrategicStoneStudy/EH_atlases.html (accessed 4.15.21). 